\title{
Duodenal diverticula occurring in a family-chance or inheritance?
}

\author{
AHUD STERNBERG \\ M.D. \\ AlEXANDER A. DEUTSCH \\ M.B., Ch.B., F.R.C.S. \\ ITAMAR KOTT \\ M.D. \\ RAPHAEL REISS \\ M.D.
}

\author{
Department of Surgery 'B', Beilinson Medical Center, Petah Tiqva 49100 and Tel Aviv University Sackler School \\ of Medicine, Israel
}

\begin{abstract}
Summary
The incidence, aetiology and possible inheritance of duodenal diverticula remain controversial. These aspects are discussed through the presentation of a family, in which duodenal diverticula occurred in a man and his two sons. To the best of our knowledge, this is the first such family documented in the medical literature. This familial occurrence may be attributed solely to the high incidence of duodenal diverticula in the general population (set by various authors at up to $14 \cdot 2 \%$ ), and, therefore, of no hereditary significance at all. We believe a screening study of the families of individuals with proven duodenal diverticula is most desirable, for it could shed light upon the controversial questions of incidence, aetiology, and inheritance patterns of duodenal diverticula.
\end{abstract}

KEY WORDS: haemorrhage, gastrointestinal, carcinoma, bronchogenic.

\section{Introduction}

To the best of our knowledge, the only familial occurrence of diverticulosis of the duodenum was noted by Chitambar in an X-ray study in 1953, when he diagnosed multiple duodenal diverticula in two sisters. We present a family in which duodenal diverticula occurred in the father and two of his sons.

\section{Case report}

A 75-year-old man was admitted because of severe recurrent gastrointestinal bleeding. He was known to have metastatic lung cancer. $\mathrm{He}$ had had a barium meal previously for dyspepsia and was also known to have a diverticulum of the duodenum. He stated that his 65-year-old physician brother also had a duodenal diverticulum, and that their father had died after emergency surgery for massive haemorrhage from a duodenal diverticulum (both diverticula were in the peri-ampullary second portion of the duodenum).

At laparotomy, generalized abdominal spread of the lung tumour was found. The duodenum had a scarred first portion, and gave rise to two diverticula, one from the anterosuperior aspect of the first part, the other from the concave peri-ampullary area of the second part, embedded in the head of the pancreas. No evidence of active bleeding from the diverticula was apparent. The patient died shortly after surgery.

We failed in our attempt to study the rest of the family. A sister and all offspring of the brothers and sister were unco-operative and claimed to be healthy.

\section{Discussion}

The incidence of duodenal diverticula according to barium meal studies varies between $0.016 \%$ (Rankin and Martin, 1934) and 5.76\% (Chitambar, 1953), whereas the autopsy studies indicate a somewhat higher average incidence, with a suprisingly wide range of variation between $0.015 \%$ (Horton and Mueller, 1933) and 14.2\% (Baldwin, 1911). We disregard Ackerman's study (1943), based upon the making of plaster casts of the duodenum in 50 cadavers, which revealed an incidence of $22 \%$, as no more recent study has come near this incidence.

The aetiology of true extraluminal duodenal diverticula remains controversial. They are rarely discovered in infants, children or young adults, but it is possible that genetic factors exist and contribute to the development of the diverticulum in later years.

The clinical and pathological features of duodenal diverticula, with regard to a congenital or an acquired origin, have been described at length (Andolf, 1951; Beals, 1937; Boyd, 1947; Edwards, 1934, 1935, 1936; Friedlander, 1937; Hansemann, 1896; Horton and Mueller, 1933; Jones and Merendino, 1960; 
TABLE 1. Probability of existence of a random, independent feature in at least three members of families of 4-10 individuals $(n)$, at three incidence values $(P)$

\begin{tabular}{lcccccccc}
\hline & \multicolumn{8}{c}{$n$} \\
\cline { 2 - 8 }$P$ & 4 & 5 & 6 & 7 & 8 & 9 & 10 \\
\hline 0.00015 & $1 \times 10^{-11}$ & $3 \times 10^{-11}$ & $7 \times 10^{-11}$ & $1 \times 10^{-10}$ & $2 \times 10^{-10}$ & $3 \times 10^{-10}$ & $4 \times 10^{-10}$ \\
0.06 & 0.0008 & 0.002 & 0.004 & 0.006 & 0.01 & 0.01 & 0.02 \\
0.14 & 0.01 & 0.02 & 0.04 & 0.06 & 0.09 & 0.12 & 0.15 \\
\hline
\end{tabular}

Localio and Stahl, 1968; Nagel, 1925; Warren and Emergy, 1943).

It is surprising that although duodenal diverticula are common, familial occurrence has been recorded only once before (Chitambar, 1953). Table 1 gives the probability of occurrence of a given feature in a man and two of his offspring (the number of affected family members $x=3$ ), assuming that it occurs independently and at random in each of these individuals. The calculation is based upon binomial distribution (b), according to Mather (1973), for families of 4-10 members $(n)$, and at three prevalence values $(p)$, which are approximations of the minimal, average and maximal prevalence values of duodenal diverticula according to various authors $(0.015 \%, 6 \%$, 14\%). $x=$ number of affected family members and $q=1-p$. The formula for the probability of observing $x$ affected family members in a family of size $n$ is:

$$
b(x, n)=\left(\begin{array}{l}
n \\
x
\end{array}\right) p^{x} q^{n-x} .
$$

Therefore, the probability of observing three or more affected members in a family of size $n$ is:

$$
\sum_{x=3}^{n} 6(x, n)
$$

For average size families of four or five members, at the minimal prevalence rate $(0.015 \%)$, the probability of at least three members having duodenal diverticula is very low: $1 \times 10^{-11}$ and $3 \times 10^{-11}$, respectively. But at a prevalence rate of $6 \%, 0.2 \%$ and $0.8 \%$ of all families of four and five members, respectively, will include at least three members who have duodenal diverticula. These figures become higher at the maximal incidence rate of $14 \%$, when $1 \%$ and $2 \%$ of all families of four and five members will include at least three members with duodenal diverticula, respectively. In other words, at the maximal, and even at the average incidence values, familial occurrence of duodenal diverticula should be quite common.

If such a screening study of the families of patients with proven duodenal diverticulum gave results that differ significantly from the figures in Table 1 , the assumptions of independent random occurrence would be disproved. A second phase study of affected families would then provide the true pattern of inheritance.

\section{Acknowledgments}

We wish to thank Dr Mitchell Snyder of the Bar-Ilan University Computer Center in Ramat Gan, Israel, for his assistance in the statistical analysis, and also Professor I. Urca, former Head of : Department of Surgery 'B', Beilinson Medical Center, Petah Tiqva, $\underset{\infty}{\infty}$ Israel, for his assistance.

\section{References}

ACKermanN, W. (1943) Diverticula and variations of the duodenum. Annals of Surgery, 117, 403.

ANDOLF, N. (1951) Etude sur l'importance clinique des diverticules $\infty$ du duodenum. Acta Chirurgica Scandinavica, 157, (suppl.) 1.

BALDWIN, W.M. (1911) Duodenal diverticulum in man. Anatomical Record, 5, 121.

BEALS, J.A. (1937) Duodenal diverticula. Southern Medical Journal, 30, 218.

BoyD, W. (Ed.) (1947) Textbook of Pathology, 4, p. 255. W. B. Saunders Company, Philadelphia.

Chitambar, I.A. (1953) Duodenal diverticula. Surgery, 33, 768.

EDWARDS, H.C. (1934) Diverticula of the duodenum and jejunum. Lancet, i, 169.

EDWARDS, H.C. (1935) Diverticula of the duodenum. Surgery, Gynecology and Obstetrics, 60, 946.

EDWARDS, H.C. (1936) Diverticulosis of the small intestine. Annals of Surgery, 103, 230.

FriedLANDER, G. (1937) Diverticula of duodenum. British Journal of Radiology, 10, 26.

HANSEMANN, D. (1896) Ueber die entstehung falscher darmdivertike. Archiv fur Pathologische Anatomie, 144, 400.

HORTON, B.T. \& MUELLER, S.C. (1933) Duodenal diverticula: An anatomic study, with notes on the etiologic role played by dystopia of pancreatic tissue. Archives of Surgery, 26, 1010.

JONES, T.W. \& MERENDINO, K.A. (1960) The perplexing duodenal diverticulum. Surgery, 48, 1068.

LoCALIO, S.A. \& STAHL, W.M. (1968) Diverticular disease of the alimentary tract. Part II: The esophagus, stomach, duodenum and $\mathrm{N}$ small intestine. Current Problems in Surgery, January 1968, p. 25. O

MATHER, K. (1973) Statistical Analysis in Biology, p. 17. Chapman N and Hall, Great Britain.

NAGEL, G.W. (1925) Unusual conditions in the duodenum and their $C$ significance: Membranous obstruction of the lumen, diverticula 0 and carcinoma. Archives of Surgery, 11, 529.

RANKIN, F.W. \& MARTIN, W.J. JR. (1934) Diverticula of the small bowel. Annals of Surgery, 100, 1123.

WARREN, H.A. \& EMERGY, E.S. JR. (1943) Duodenal diverticula: With special reference to symptomatology. Gastroenterology, $1, \tau$ 1085 .

(Accepted 1 June 1983) 